\title{
Plant Endophytes and Epiphytes: Burgeoning Sources of Known and "Unknown" Cytotoxic and Antibiotic Agents?
}

Authors

David J. Newman ${ }^{1 \#}$, Gordon M. Cragg ${ }^{2 \#}$

Affiliations

1 NIH Special Volunteer, NCI Natural Products Branch, Wayne, PA, USA

2 NIH Special Volunteer, NCI Natural Products Branch, Gaithersburg, MD, USA

Key words

endophyte, taxol, camptothecin, vinca alkaloids, maytansine, fermentation

received

October 10, 2019

accepted after revision

January 12, 2020

published online

February 5, 2020

Bibliography

Planta Med 2020; 86: 891-905

DOI 10.1055/a-1095-1111

ISSN 0032-0943

(C) 2020. Thieme. All rights reserved.

Georg Thieme Verlag KG, Rüdigerstraße 14, 70469 Stuttgart, Germany

\section{Correspondence}

Dr. David J. Newman

Newman Consulting LLC

664 Crestwood Road, 19087 Wayne, Pennsylvania, USA

Phone: + 16109719784 , Fax: + 16109712526

djnewman664@verizon.net

\begin{abstract}
In the last 20 or so years, the influence of endophytes and, quite recently, epiphytes of plants upon the compounds found in those plants, which were usually assumed to be phytochemicals produced by the plant for a variety of reasons, often as a defense against predators, is becoming more evident, in particular in the case of antitumor agents originally isolated from plant sources, though antibiotic agents might also be found, particularly from epiphytes. In this review, we started with the first report in 1993 of a taxol-producing endophyte and then expanded the compounds discussed to include camptothecin, the vinca alkaloids, podophyllotoxin, and homoharringtonine from endophytic microbes and then the realization that maytansine is not a plant secondary metabolite at all, and that even such a well-studied plant such as Arabidopsis thaliana has a vast repertoire of potential bioactive agents in its leaf epiphytic bacteria. We have taken data from a variety of sources, including a reasonable history of these discoveries that were not given in recent papers by us, nor in other papers covering this topic. The sources included the Scopus database, but we also performed other searches using bibliographic tools, thus, the majority of the papers referenced are the originals, though we note some very recent papers that have built on previous results. We concluded with a discussion of the more modern techniques that can be utilized to "persuade" endophytes and epiphytes to switch on silent biosynthetic pathways and how current analytical techniques may aid in evaluating such programs. We also comment at times on some findings, particularly in the case of homoharringtonine, where there are repetitious data reports differing by a few years claiming the same endophyte as the producer.
\end{abstract}

\section{Introduction}

Although the presence of endophytic and epiphytic microbes in/ on plants has been known for many years, with the review by Tan and Zou [3] ascribing the first formal recognition of endophytes to work conducted on the plant "darnel" in Germany in 1904 by Freeman and Marshall [4], the systematic investigation of the properties of these microbes has been relatively recent, with one such report being from Petrini and Petrini published in 1985 dealing with Xylarious fungi as endophytic microbes [5]. Investigation of these organisms as potential sources of novel bioactive agents continued at a relatively low rate until the report by Stierle et al. in 1993 on the isolation of an endophytic fungus from the tree Taxus brevifolia that produced low levels of taxol ( $\vee$ Fig. 1 ) on initial fermentation [6]. We are using the chemical name taxol, given to the

\# Note: Both authors sequentially retired from the position of Chief of the NCl's Natural Products Branch in 2015 and 2004, respectively. They are currently honorary NIH Special Volunteers associated with the Natural Products Branch. 


\begin{tabular}{|c|c|}
\hline \multicolumn{2}{|c|}{ ABBREVIATIONS } \\
\hline BGC & $\begin{array}{l}\text { biogenetic gene cluster; the cluster of genes that } \\
\text { provide the necessary biochemistry to produce } \\
\text { the metabolite }\end{array}$ \\
\hline ITS & $\begin{array}{l}\text { rRNA gene internal transcribed spacer region (see } \\
\text { Nilsson et al. [1]) }\end{array}$ \\
\hline MIBiG & $\begin{array}{l}\text { minimum information about a biosynthetic gene } \\
\text { cluster (see Kautsar et al. [2]) }\end{array}$ \\
\hline $\mathrm{NCl}$ & $\begin{array}{l}\text { National Cancer Institute; the largest Institute in } \\
\text { the US Government's National Institutes of Health }\end{array}$ \\
\hline US FDA & United States Food and Drug Administration \\
\hline
\end{tabular}

compound by the discoverers, though some papers referenced may use the generic name of the drug paclitaxel instead. Since we are dealing with the chemistry and microbiology of the compound, the chemical name fits best.

On subsequent fermentation, the level of production of taxol by this fungus, which was subsequently named Taxomyces andreanae, was very low, though later work published in 1995 utilizing endophytes collected from many yews (genus Taxus) growing in the NW of the USA led to studies that proved the production of taxol ( $\triangleright$ Fig. 1) plus other not then identified taxane-like molecules. However, production of taxol was confirmed by many analytical techniques including specific monoclonal antibodies [7].

Since these initial discoveries, the topic of microbial involvement in the "production of medicinal agents in/by plants" has led to a large number of publications, and hopefully by the end of the review, cases will have been made that in some instances, the producer is in fact microbial, while in others, they may be involved in a bipartite relationship, and in others, the "jury is still out"!

\section{Definitions of Endophyte and/or Epiphyte}

The definition of endophyte that we are using is as described by Stierle et al., viz., "bacteria and fungi that colonize intercellular and/or intracellular plant tissue and apoplastic compartments" [6]. Epiphytes, in contrast, are microbes that can be isolated from the surface(s) of leaves, roots, etc., without disturbing or cutting the surface(s). Conventionally, endophytes are isolated by aseptic cultivation of internal plant tissues, usually by simply "plating" such aseptically removed tissues from underneath surface sterilized materials on suitable growth media. Epiphytes are obtained by simply placing the unsterilized surface of a leaf, or other plant surface tissue, on suitable media. We have deliberately included both nominal sources since at times, it may be difficult to ascertain from a publication whether or not the original microbe was "associated with the roots/rhizosphere" or was isolated from internal root tissue(s), or from a leaf surface, etc. Therefore, we may well discuss data from these "nominal sources" together, though where there are no discrepancies, we will use the source (s) listed in the publications that are referenced.

We will also present a discussion on epiphytic microbes, which can include microbes in the rhizosphere of plants that may involve

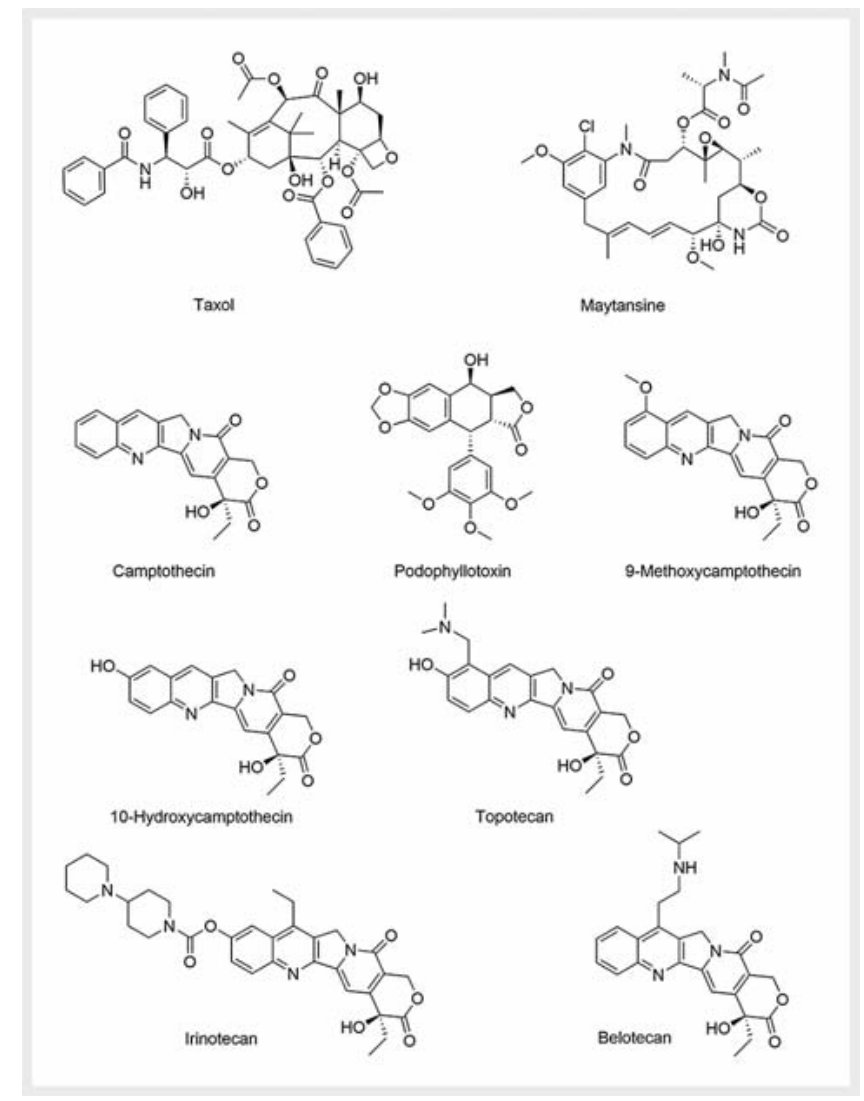

- Fig. 1 Bioactive compounds and derivatives from "plant sources" I.

both endophytic and epiphytic organisms. In the case of maytansine ( $\bullet$ Fig. 1), microbial production is definitive from the detailed evidence that will be given. Such an "epiphytic production" may well be contributing in at least two ways: (1) producing microbial metabolites originally thought to be from the plant and/or (2) producing "elicitors in the widest sense of the term", i.e., chemical agents that can modify the production of compounds produced by endophytes or even other epiphytes. Direct influence on other epiphytes is still conjecture, but similar effects are well known in microbe/microbe interactions, with some examples being mentioned at the end of the review

In the sections below, we will take selected examples, including later work with taxol-producing microbes, demonstrating that endophytic, and at times epiphytic microbes isolated from wellknown "medicinal plants", have the ability to produce, in some cases, low to reasonable levels of the same agent as those first found by classical methods from the plant.

\section{Differences between "Phytochemical Isolation" and Bioactivity-Driven Isolation}

In order to show the differences and how as techniques have improved, similarities have occurred, we will give three examples of each type so that readers can see how they differ in the thinking behind each process. 


\section{Phytochemical isolation}

As a relatively modern example of phytochemical analyses/minimal isolation, Cai et al., in a 2011 paper [8], simply described how after making extracts of the dried powdered plant material using a variety of organic and aqueous solvents, they then used what an analytical chemist would call "spot tests" to determine what chemical classes were present, and simply reported these findings. An extension of this process was used by Kumar and Simon [9] in a paper published in 2016, where using extracts prepared in a similar manner to Cai et al. [8] they looked for the presence of wide classes of chemical compounds. They then checked these crude extracts for in vitro antibiotic activity against Escherichia coli and Pseudomonas aeruginosa, but even after finding positive results, the extracts were not further identified chemically, simply activities were reported.

In a very recent report in 2019, however, Cao et al. [10] demonstrated that by use of current metabolomics strategies, it was possible to link mass spectral identification of extracts to particular metabolites. This was not bioactivity-driven isolation but analytical techniques were used to begin to characterize potentially active agents in a medicinal plant.

\section{Bioactivity-driven isolation}

The first two of the three examples below demonstrate that following the bioactivity of fractionated extracts made using a variety of chromatographic techniques led to identification of novel agents, or to prior known agents with a different pharmacological activity. The first example had potential as a lead to a novel antitumor treatment, and the second, a potential treatment for cystic fibrosis.

In the first, Fuller et al. demonstrated the use of the NCl-60 cell line screen to isolate an unusual halogenated monoterpene from a red alga collected in the Philippines that exhibited an interesting $\mathrm{NCl}-60$ cell line pattern [11]. The second example by Chen et al. demonstrated the isolation of known molecules with a previously unknown potential as inhibitors of the cystic fibrosis transmembrane conductance regulator, when an assay using that target was used to follow biological activity of the fractions [12].

The third example in bioactivity-driven systems is somewhat different due to the very rapid advances in mass spectrometry, ultrahigh-performance liquid chromatography, and coupled computerization. In 2018, Nothias et al. published a paper in the Journal of Natural Products [13] that combined bioactivity-driven isolation with computerized molecular networking to identify previously unknown compounds in bioactive fractions. Their short description (quoted from their abstract) is as follows: "the concept of bioactive molecular networking to find candidate active molecules directly from fractionated bioactive extracts. By employing tandem mass spectrometry, it is possible to accelerate the dereplication of molecules using molecular networking prior to subsequent isolation of the compounds, and it is also possible to expose potentially bioactive molecules using bioactivity score prediction.".

\section{Summary of the differences}

From these examples, it can be seen that in the case of phytochemical isolation, samples that range from fractionated extracts through to purified compounds are simply tested against what- ever screens are available in the investigator's and/or a collaborator's laboratory. Use of this system accounts for the very large number of compounds/extracts from plant sources reported to have antioxidant activities, since that assay is a very simple in vitro assay, but bears little or no relationship to an active drug lead.

In contrast, in the case of bioactivity-guided fractionation/ identification, although the starting point is similar, the only compounds that are finally purified and identified are those that show a well-defined activity in a validated in vitro screen prior to further assays using suitable in vivo screening processes.

We should also point out that the principle of bioactivity-driven isolation was a well-known process dating from the early $1950 \mathrm{~s}$ in the pharmaceutical industry's search for antibiotics, with similar processes but using microbes instead of cell lines/enzyme targets, and following up with rodent infection models in animals with functioning immune systems. Active agents would then enter the normal predevelopment pipeline for noncancer drugs.

\section{A caveat}

Even using bioactivity-driven systems, the same compound may well give a positive response in a variety of defined screens, and this discovery has led to the definitions of the PAINS [14] and IMPS listings of compounds [15]. Both of these papers are well worth reading by any scientist interested in bioactive natural products, irrespective of the target.

\section{Initial Studies with Taxol}

The presence of the base diterpenoid structure (a taxane) was known to be in many plants from phytochemical analyses, but it was not until extracts from the initial $\mathrm{NCl}$ funded plant collection programs, which included Taxus samples from the Olympic Peninsula in the North West of the USA (early 1960s), were tested against murine cell lines, purified, and then followed by in vivo assays initially using murine tumors in mice that bioactivity was confirmed. Thus, this work was definitely bioactivity driven, with later data demonstrating bioactivity against human tumor cell lines in “immune-suppressed mice”. In subsequent work, both plant and marine invertebrate extracts produced by academic laboratories were tested by $\mathrm{NCl}$ contractors by following activity against human tumor cell lines in "immune-suppressed mice" studies. These led to "systematic collections and bioactive isolation programs" searching for antitumor active agents from such sources. Ultimately, the collections and extractions were made by $\mathrm{NCl}$ contract collectors and assayed in contract laboratories using the $\mathrm{NCl} 60$ cell line assay. Later, these extracts/fractions were made available to qualified investigators worldwide. We will not provide further details as these programs are very well documented in the $\mathrm{NCl}$ websites.

\section{“Endophytes/epiphytes" and taxol production}

As mentioned above, initial reports from the Strobel laboratory in 1993 [6] and subsequent work from that group [7] demonstrated that taxol could be found in a variety of endophytes, including some endophytes that were isolated from plants not reported to contain taxol [16]. This later work suggested that the presence of this compound in an endophyte may not be due to carryover from 
the host's plant tissue. Over the years, since the initial report in 1993, well over 200 endophytic fungi belonging to over 40 genera and several orders, mostly Ascomycota and Deuteromycota, have been reported to produce taxol, and taxol-producing fungi have been isolated from plants of taxonomically diverse, non-Taxus species that do not contain taxol or intermediates when extracts were analyzed.

We should point out at this stage, that in 2013, a report from a German group on their reinvestigation of the nominal producing culture from Stierle et al. [6] stated that they could not find any taxol-related genes [17]. However, a careful reading of that report showed that this group had not sequenced the original Stierle isolate, but a strain held in a European collection that could not be traced back to the original Stierle culture, thus, this data is suspect.

Although formally published in print in 2016, the review by Chen et al. [18] was first available on the web in mid-2014 and contains an excellent summary with references of the then reported endophytic fungi that produced taxol on fermentation. The tables in this review, though not reproduced here for both copyright and spatial reasons, are well worth reading by interested scientists. It also includes a substantial number of other cytotoxic agents from various chemical classes produced by fermentation of endophytic fungi, including camptothecin derivatives and podophyllotoxin ( $\bullet$ Fig. 1). These compounds with other examples will be discussed later in the review. Other publications also contain listings of reported bioactive natural products produced by endophytes/epiphytes and these will be noted as relevant.

There are several genetic and (a)biotic parameters that may affect the concentration of taxanes, including geographical and ecological diversity, plant age, and the types of plant tissues these molecules accumulate in. For example, a correlation was found between the amount of taxol in different Taxus plants and tissues and the number of endophytic fungal species, perhaps demonstrating host-endophyte interplay $[19,20]$. The metabolic profile of Taxus plants also varied by location, suggesting the ecosystem might have an effect on this plant-endophyte relationship. Somjaipeng et al. [21] also reported different yields of taxol when $\mathrm{pH}$ or elicitors, such as serine and salicylic acid, were varied during fermentation.

\section{Taxol production by endogenous fungi from Taxus media}

In 2011, Soliman et al. reported on the isolation and characterization of a fungal endophyte from Taxus media [22], indicating that there could be at least two different biosynthetic routes to "fungal taxol" as a result of initial genomic studies on the isolated endophyte Paraconiothyrium SSM001. In 2013, Soliman continued with two excellent reports implying that interactions between other microbes in the plant with Paraconiothyrium SSM001 could lead to increased production of taxol, where bark extracts added to the fermentation gave a 30 -fold increase in fungal taxol levels [23]. Table 1 (in [23]) in that particular report shows the various levels achieved with different supplemented media. The other paper in 2013 [24] demonstrated modulation of transcription of plant genes related to taxol plant production, when levels of the fungus were altered by treatment with external fungicides. Then in 2015, Soliman et al. [25] presented significant evidence that this endophyte produces taxol that is held externally in lipid bodies in cracks in the protective bark layer where the plant branches during growth. Such cracks permit the entry of lignicolous fungi, and the endophytic taxol is an in situ protective measure against attacking fungi. They followed this initial observation by demonstrating that a byproduct of lignin degradation that is volatile (methyl chloride), and is produced by attacking lignicolous fungi, induces the production of taxol by this endophyte. A later paper in 2018 introduced evidence that this particular endophyte would lose a significant amount of taxol biosynthetic capability, together with production of a green pigment if exposed to light before fermentation [26]. Thus, metabolites produced by these endophytes appear to affect and, perhaps also in some cases, effect the chemical defense of the plant host against pathogens, insects, and herbivores.

\section{Non-taxaceae sources of taxol}

Podocarpus gracilior endophytes

The first plant reported that "produced taxol" but was not from the Taxaceae family was Podocarpus gracilior or the African Fern Pine, which was reported in 1999 by Stahlhut et al. [27]. What was also of interest is that this plant was purchased from a commercial nursery in California, not obtained from a wild collection program.

In 2018, El-Sayed et al. [28] reported that three endophytes identified as Aspergillus terreus, recovered from cork, leaves, and twigs of $P$. graciliors, produced taxol. Interestingly, when growing fungal cultures were treated with surface sterilized leaves, taxol production increased by 2 - to 3 -fold. One possibility is a physical interaction of the fungi with other (dead?) microbes on the leaf surface. Following on from this discovery, in 2019, the group published a second paper [29] in which they identified three proteins that were exponentially suppressed during subculturing. On the subsequent addition of sterilized leaves of the tree, as mentioned in the preceding paper, production of taxol resumed. The three proteins were annotated as "ribosome biogenesis proteins YTM and microtubule-assembly proteins that belonged to the WD40 superfamily". The authors are now looking for suitable promotors that may control the production of these proteins. Interestingly, they also observed a loss of melanin production as taxol production decreased, which might also point to a reduction of acetyl-CoA levels.

\section{Taxol from endophytic Aspergillus fumigatus and Altenaria tenuissima}

Another Egyptian group published two recent papers on taxol production from endophytes. These were isolated from a collection of Egyptian-sourced plants that were not part of the Family Taxaceae. In 2017, Ismaiel et al. [30] reported that Aspergillus fumigatus strain TXD105 isolated from the bark of Taxodium distichum, and Alternaria tenuissima strain TER995 isolated from the bark of Terminalia arjuna, produced taxol on fermentation. The identities of both fungal strains were confirmed genetically using ITS and deposited in GenBank. Fermentation parameters were investigated and yields for taxol were in the range of $300 \mu \mathrm{g} \cdot \mathrm{L}^{-1}$ for 
TXD105 versus $125 \mu \mathrm{g} \cdot \mathrm{L}^{-1}$ for TER995. These fall towards the higher end of figures for comparable endophytes, which are well described in the paper's conclusions. Interestingly, one of the authors is associated with the Egyptian Nuclear Research Center in Cairo, and the following year, El-Sayed et al. published the results of a series of very well-documented fermentation studies looking at media composition, UV, and nuclear irradiation on the levels of taxol production [31]. In those fermentation studies, they were able to increase the levels by 16 and $20 \%$, respectively, for TXD105 and TER995. This study is perhaps the best-designed fermentation program so far published on the production of taxol from endophytic microbes and augurs well for future studies.

\section{Taxol production by endophytic Penicillium aurantiogriseum NRRL 62431}

In 2014, Yang et al. [32] reported on the total genomic analysis of an endophytic Penicillium aurantigriseum isolated from freshly harvested hazelnuts collected in Oregon, USA. These were from the tree Corylus avellane, which had previously been reported as containing taxol in leaf extracts [33]. A complete genomic analysis was performed and showed differences in the genes involved in taxol biosynthesis when compared "head to head" with the corresponding genes in Taxus baccata. Recent horizonal gene transfer is therefore improbable but one cannot rule out a common ancestor that then evolved separately.

\section{Taxol from non-endophytic Aspergillus flavipes}

In 2019, El-Sayed et al. reported their studies [34] on the production of taxol in saprophytic and endophytic fungi from different sources, testing 50 fungi for production of taxol. Using Aspergillus flavipes, ATCC 24487, which was first described in 1911 in France [35], they demonstrated the production of taxol with a fivefold amplification by the addition of the synthetic antifungal agent fluconazole. Interestingly, treatment with low levels of this agent restored taxol production that was tailing off after the 10th subculture. Though this fungus was not isolated directly from the narrow taxane-producing taxonomic group composed mainly of plants of the genus Taxus, the researchers speculated that taxane BGCs may well have evolved to protect plants from fungal pathogens and/or taking up "free fungal taxol" as a protective agent. This paper also contains an excellent table of reported fungal producers of taxol, with endophytes isolated from plants ranging from Taxus species to "Spanish Moss" or Tillandsia usneoides and even including Phoma betae isolated from Ginkgo biloba, which interestingly had the highest yield on fermentation, almost comparable to that found on the fluconazole amplification of $A$. flavipes. As mentioned earlier with different papers, reproduction of the table of fungal taxol producers is not feasible but the paper is one available in scientific libraries.

\section{Attempts to bioengineer microbial taxol production systems}

Efforts to engineer the biosynthesis of the genes within taxol-producing endophytes or by use of other heterologous hosts, such as E. coli and Saccharomyces cerevisiae, have provided some insights on how to produce more taxol. For example, the overexpression of the Taxus taxadiene synthase under the control of a specific fungal promoter increased taxol production in Ozonium sp. EFY21 5-fold [20]. In another example, stable strains of Nodulisporum sylviforme obtained via mutagenesis were used to produce protoplasts with increased taxol yields by up to $64 \%$ [36]. The engineering of $E$. coli and $S$. cerevisiae to produce the taxol intermediate taxadiene has led to its increased production to approximately $1 \mathrm{~g} \cdot \mathrm{L}^{-1}$ [37] and $72.8 \mathrm{mg} \cdot \mathrm{L}^{-1}$ [38], respectively. By some clever bioengineering, the Stephanopolus group at MIT produced a stable co-culture of $S$. cerevisiae and $E$. coli that yielded up to $33 \mathrm{mg} \cdot \mathrm{L}^{-1}$ of oxygenated taxanes, including some that had never been obtained by fermenting microbes, using a simple carbon source [39].

Although these efforts may in due course reduce the requirements for specialized environments and compartments for optimal taxane production, the biosynthetic pathway has several metabolic bottlenecks and, what is often forgotten, provisions for increased production of early biosynthetic intermediates. In spite of these drawbacks, researchers remain hopeful, because taxol production may still be optimized using metabolic engineering and other strategies, including modification of regulatory elements, and better understanding the epigenetics and crosstalk between the plant host and endophyte(s), as microbial systems are not single entities but live in a world full of competition for resources.

\section{Camptothecin(e)}

The isolation and initial biological properties and structure of the quinoline alkaloid camptothecin ( $\triangleright$ Fig.1) were first reported from the stem bark of the Chinese plant Camptotheca acuminata Decaisne (Nyssaceae) by Wall et al. in 1966 [40]. This compound acts as a potent antitumor agent via stabilization of the transient covalent complex between DNA and the enzyme DNA topoisomerase I, which prevents DNA and RNA synthesis. Camptothecin also inhibits the replication of human immunodeficiency virus (HIV) $[41,42]$, but, to the best of our knowledge, was never used clinically for this purpose.

Camptothecin itself was too toxic for drug use due to the cleavage of its lactone by plasma esterases and poor water solubility $[43,44]$. Further studies on the structure-activity relationships of the parent molecule led to the discovery of naturally occurring analogues, such as 9-methoxy-camptothecin and 10-hydroxycamptothecin, and, subsequently, to the clinically used drugs topotecan, irinotecan, and belotecan ( $\bullet$ Fig. $\mathbf{1}$ ). For early details through late 2003 on topoisomerase I agents, including camptothecin, the review by Cragg and Newman published in 2004 can be consulted [45], with an updated version by the same authors published in 2015 as part of a chapter in "The Practice of Medicinal Chemistry" [46]. In addition to the modifications of camptothecin mentioned above that have become drugs in their own right, in late December 2019, a chemically modified camptothecin linked to a monoclonal antibody as an antibody drug conjugate was approved under the name of traztuzumab deruxtecan (Enhertu ${ }^{\circledR}$ ) by the US FDA, but the structure is not given due to its overall complexity.

Although there are current available plant sources such as C. acuminata and Nothapodytes nimmoniana, the maximum yields 
are on the order of $0.3 \%$ dry weight [47]. Major problems with the natural source(s) can be summed up in the following phrases: grow in restricted areas; have prolonged juvenile phases; and require years of cultivation for commercial yields of camptothecin. As a result, these and other medicinal plants have been overharvested for the pharmaceutical industry [48]. As a result, if there is a viable microbial source for the large-scale fermentation of camptothecin and analogues, it could be both beneficial not only for commercial purposes, but also for the environment.

\section{Endophytic production of camptothecin(s)}

As was seen in the discussion on taxol production, it is common when fermenting "producing endophyte-related cultures" for the yields to decrease on continuous subculture. This is also the case with reports on camptothecin producing cultures. Such a loss may be due to the lack of stimuli from the host. An excellent example of such an effect was shown in data from fermentations of cultures that produced flavonolignans, published by the Oberlies group in 2014 [49]. In this case, sterile filtrates of washes from leaves of the host plant restored full production following subculturing. Another potential reason is inhibition of the producing organism by the product itself as a protective measure, and this mechanism was recently reported in a fungus that produced camptothecin [50].

There have been a number of reports of different endophytes isolated from plants that have the ability to produce low levels of camptothecin such as other plants of the genera Nothapodytes and also from Miquelia dentate (Icacinaceae) [51]. In the case of Nothapodytes foetida, the yield from this plant is very low, though the endophytes, Neurospora crassa and Entrophospora infrequens, from N. nimmoniana are able to produce camptothecin [52].

In 2009, Kusari and coworkers isolated an endophytic fungus, Fusarium solani, from the inner bark of the $C$. acuminata plant and detected the presence of camptothecin and some previously reported analogues [53]. Since other strains of this particular fungus isolated from different locations did not produce these secondary metabolites, it is possible that the BGCs involved in producing these compounds may have come from the host via horizontal gene transfer or, alternatively, the gene clusters involved needed some "activator(s)" or removal of some "inhibitor(s)" not "provided" under the growth conditions used. The production of camptothecin and 9-methoxy-camptothecin decreased after each subculture, but, interestingly, 10-hydroxy-camptothecin was not seen until the 4th subculture and did not appear to decrease until the experiment ceased at the 7th subculture.

In 2012, Kusari et al. extensively discussed the origins of secondary metabolites in endophytes, with the greater than 100 citations to this paper being worth revisiting in the future [54]. Later studies on C. acuminata and F. solani by Kusari and coworkers support the balanced antagonism hypothesis, whereby the endophyte becomes self-resistant to ensure its protection against the camptothecin produced by both the plant and endophyte [50]. The key plant enzyme strictosidine synthase [55] was later determined to be a gate keeper to the biosynthesis of camptothecin in endophytic F. solani; thus, one may well consider a plant-endophyte signaling mechanism being used by plants as a second line of defense against a wide variety of insects [56].

\section{Supplementation studies with camptothecin- producing endophytes}

Though the following papers are not in strict chronological order, they show the effect of modified fermentation parameters. As mentioned earlier with the work on supplemented production of flavolignans, a variety of relatively recent publications have demonstrated that the levels of camptothecin in endophytic cultures can be modified by suitable techniques. Some of these, though not referenced as such, date back more than 30 plus years where techniques in the fermentation industry that were never formally published due to their being very well-known were "rediscovered and published as being novel" by academics after 2005 .

In the introduction to their paper in 2015, Pu et al. gave a short history of reports of endophytic microbes that could produce camptothecin on isolated culture [57], but in almost all cases, the yields decreased with subculture. However, they had reported 2 years earlier that one of their isolates, Trichoderma atrovide LY357, did show increased yields when elicitors/adsorbent resins were added to the culture broth [58]. In their 2015 paper referenced above, the group reported on the isolation and subsequent fermentation of the endophytic bacterium Paenibacillus polymyxa LY214 from the camptothecin-producing plant C. acuminata. They confirmed taxonomy of this bacterium using standard 165 rDNA data for the endophyte, demonstrating higher than 99\% homology with other $P$. polymyxa strains. Although substantial decreases in camptothecin production were seen on subsequent subculturing, a 15- to 30-fold increase in the camptothecin yield was seen using optimized fermentation conditions, use of potential biosynthetic precursors (secologanin and tryptamine), and the addition of XAD16 as an absorbent. These were used in combination and applied to optimize production after the 7th and 8th subcultures. Yields under these conditions were on the order of $12-23 \mu \mathrm{g} \cdot \mathrm{L}^{-1}$.

Furthermore, in two recent papers, Venugopalan and Srivastava reported a 10.6-fold increase in the production of camptothecin when ethanolic extracts of the plant Catharanthus roseus were added to a suspension culture of $F$. solani $[59,60]$. A possible explanation could be that the $C$. roseus extract might have contained strictosidine, a known rate-limiting step in camptothecin biosynthesis. Concomitantly, in 2015, Govindwar's group reported the application of computerized fermentation techniques to the problem of camptothecin production in a complex medium. By using the fungal endophyte Fusarium oxysporum Kolhapurensis, isolated from Nothapodytes nimmonia Mabb. Grahm, a known producing plant [61], levels in the optimized medium ranged from $283 \mathrm{mg} \cdot \mathrm{L}^{-1}$ and decreased to $33 \mu \mathrm{g} \cdot \mathrm{L}^{-1}$ by the 8th subculture. It is possible that the initial concentration might be the highest yet reported, however, information as to the provenance of the culture used was lacking, so the absolute effect of supplementation cannot be determined.

Very interestingly, in 2016, the same basic group [62] reported that using a mixed culture of two endophytic fungi (Colletotricum fruicola SUK1 and Corynespora cassiicola SUK2), which were isolated from the same plant specimen as in their 2015 paper (above), when fermented under complex media conditions, and knowing that each could produce camptothecin independently, demonstrated a yield of approximately $146 \mathrm{mg} \cdot \mathrm{L}^{-1}$. If the mixed cultures were used, then maximal yields appeared at 7 days, com- 


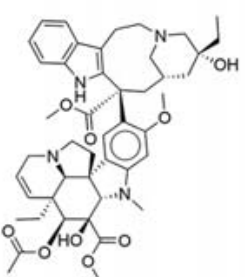

Vinblastine

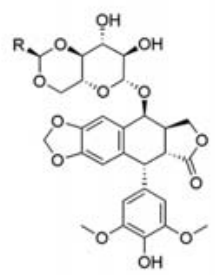

Etoposide, $\mathrm{R}=\mathrm{CH}_{3}$ R = a-thiazole

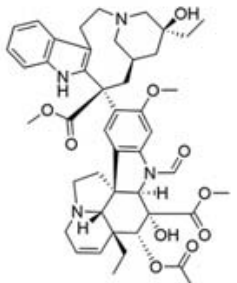

Vincristine

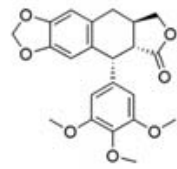

Deoxypodophyllotoxin

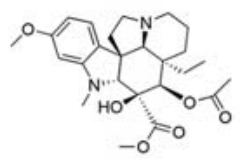

Vindoline

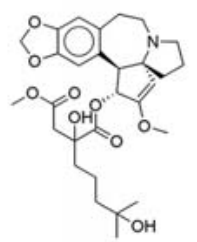

Homoharringtonine

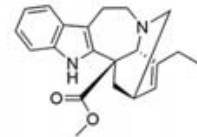

Catharanthine

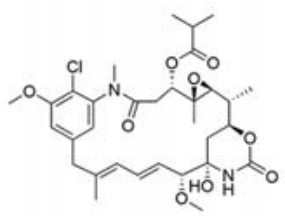

Ansamitocin P3

- Fig. 2 Bioactive compounds from "plant sources" II.

pared to 15 and 20 days for the individual microbes under the same conditions. What "signaling agents" could have been generated, be they biosynthetic intermediates or promotors/inhibitors, is not known or reported to date, but "talk between organisms" is now well documented and investigators tend to "forget" that microbes do not exist alone, they are parts of consortia.

It would be interesting to be able to perform a thorough fermentation program utilizing the reported camptothecin producers, but what is definitely of interest is that Bhalkar et al. [61, 62] used fungal spores to begin their fermentations, so there was no potential for carryover from the plant source in those experiments.

\section{Is a Plasmid Involved?}

In 2017, Indian researchers reported that a plasmid appeared to be involved in the production of camptothecin by endophytic bacteria isolated from the plant Pyrenacantha volubilis Hook. Unusually, these were all Bacillus species, not fungi. Using acriflavine to "cure" the microbe of the plasmid, the "cured Bacillus" no longer produced camptothecin [63], but subsequent transformation with the plasmid restored production. As of the end of 2019, no further work has been reported on this discovery.

\section{Vinca alkaloids}

The vinca alkaloids, vinblastine and vincristine ( $\bullet$ Fig. 2), were first reported in the 1960s from classical phytochemical searches using the leaves of the Madagascar periwinkle $C$. roseus due to earlier reports that the plant had antidiabetic properties, which turned out to be incorrect [64]. These compounds were later found to have potent activity against leukemia and Hodgkin's lymphoma, as well as some activity against selected solid tumors. The mechanism(s) of action of these dimeric monoterpene indole alkaloids included inhibition of cancer cell proliferation by preventing the dimerization of microtubules, blocking mitosis, and causing apoptosis. The only current source of these FDA-approved drugs is from $C$. roseus leaves, in which they are present in very low yields. To meet the worldwide demand of approximately $3 \mathrm{~kg}, 300$ tons of dried leaves are required, and the high prices of these drugs reflect the difficulty in accessing these compounds [64].

In attempting to increase yields, growing $C$. roseus cell suspension cultures were supplemented with phytohormones, hairy roots, and transgenic tissue in attempts to increase the concentration of at least the monomers of these dimeric alkaloids and/ or the vinca alkaloids themselves. However, none of these attempts were viable commercially. De novo synthetic schemes for these structures are both low yielding and complex, which effectively eliminated total synthesis as a viable option for the commercial production of these compounds [64]. Some semisyntheses were developed that used extractable precursors from $C$. roseus, but again, commercial viability was debatable. Due to the increasing demand for these drug entities, researchers were prompted to search for more viable options [64].

Early reports on the production of vincristine by endophytic F. oxysporum were published in 2000 in the Chinese journal Zhongcaoyao by Zhang et al. [65] and referenced by Gunatilaka in 2006 [66]. A later study by the same group was published in the same journal in 2004 [67]. Two years before the 2000 report mentioned above, in 1998, the same group reported the isolation of vinblastine from an endophytic Alternaria sp. strain 97CG1 [68]. In 2013, Kumar and co-workers reported the production of both vinblastine and vincristine from an endophytic $F$. oxysporum with levels of $76 \mu \mathrm{g} \cdot \mathrm{L}^{-1}$ for vinblastine and $67 \mu \mathrm{g} \cdot \mathrm{L}^{-1}$ for vincristine [69]. Quoting from their paper, these figures are comparable to those obtained from plant-based extraction techniques. The same year, that group also reported bioconversion of vinblastine into the less 
abundant vincristine by incubating vinblastine with the same endophytic Fusarium species [70]. This latter result does raise a question as to what the actual maximal levels were of either alkaloid produced in their fermentation experiments quoted above.

In contrast to the levels found by Kumar et al., in 2016, Palem et al. [71] reported the production of vinblastine and vincristine by another endophytic fungus, Talaromyces radicus, also isolated from $C$. roseus. In their experiments, levels of $70 \mu \mathrm{g} \cdot \mathrm{L}^{-1}$ and $670 \mu \mathrm{g} \cdot \mathrm{L}^{-1}$, respectively, were achieved. The latter figure is a highly significant improvement in the production of vincristine when compared to the $67 \mu \mathrm{g} \cdot \mathrm{L}^{-1}$ of vincristine reported by Kumar et al. referenced above. Palem et al. also demonstrated that the yields could vary by a factor of close to 100 depending upon the media used, and it should also be pointed out that they chose their endophyte by genomically searching for the presence of the gene encoding, the first critical step in the biosynthesis of terpenoid indole alkaloids, a reaction catalyzed by tryptophan decarboxylase, which is encoded by a single gene in $C$. roseus. Thus, they made a very careful selection from the 22 endophytes isolated rather than simply fermenting in a small number of media and looking for any vinca alkaloids produced.

To close this emphasis on vinca alkaloid production by endophytes, a very recent paper by Anjum and Chandra [72] showed that the endophytic bacterium Microbacterium sp., isolated from C. roseus, produced vindoline ( $\bullet$ Fig. 2 ) and, using modern fermentation techniques, yields of $\sim 80 \mu \mathrm{g} \cdot \mathrm{L}^{-1}$ of this intermediate could be obtained relatively easily.

\section{Host-endophyte interactions to increase vinca alkaloid plant levels}

One could consider this section to be the reverse of the others in this overall review, as it demonstrates the "effect of endophytes upon production of metabolites by the whole plant", since these experiments demonstrated evidence that host-endophyte interactions(s) can induce the production of vinca alkaloids. In a series of very well-designed experiments, Pandey et al. [73] inoculated endophyte-free, low vinca alkaloid-producing $C$. roseus genotype (cv. Prabal) seedlings with two endophytes, Curvularia sp. CATDLF5 and Choanephora infundibulifera CATDLF6. Using genetic marking, these treatments resulted in the increased expression of monoterpene indole alkaloid genes, which included the transcriptional activator "octadecanoid-responsive Catharanthus AP2-domain protein and vacuolar class III peroxidase", known to be involved in the dimerization of vindoline and catharanthine ( $\vee$ Fig. 2) to produce vinblastine and vincristine [73]. In addition, the leaves of the seedlings inoculated with CATDLF5 and CATDLF6 had a 4 -fold and 2-fold increase in the production of vindoline, respectively. These endophytes also promoted plant growth as well as increased the rates of photosynthesis and transpiration, resulting in an overall increase of biomass and key metabolites. Thus, understanding the relationship between a host and its endophyte may provide deeper insights into how to improve the production of vinca alkaloids.

\section{Podophyllotoxin}

Podophyllum peltatum Linnaeus and Podophyllum emodi Wallich have had a history of use in folk medicine for over two centuries for the treatment of warts and "perhaps what might have been a form of skin cancer". The isolation of the most abundant active principle, podophyllotoxin ( $\bullet$ Fig. 1), in the 1880 s was first reported by Podwyssotzki [74], though it was not until 1932 that the base structure was reported by Borsche and Niemann [75]. Podophyllotoxin was reported to have antitumor, antiviral, insecticidal, and anti-inflammatory activities, and based on these activities, two of the many semisynthetic derivatives, etoposide (VM 26) and teniposide (VP 16-213) ( Fig. 2), were approved by the FDA for the treatment of lymphomas and bronchial and testicular cancers $[46,76]$.

Compared to recovery from the plant, the chemical synthesis of podophyllotoxins is not economic and although this compound has been reported from several plant genera, for example, Sinopodophyllum, Podophyllum, Juniperus, Linum, Thuja, Nepata, Teuricum, Hyptis, Jeffersonia, Dysoma, and Diphylleia, a number of these potential sources are endangered for anthropogenic reasons [77, 78]. As a result, podophyllotoxin is in high demand, especially since it is the main precursor in the synthesis of the approved drugs etoposide and teniposide [76].

In 2003, a Chinese group led by Yang [79] reported on the production of podophyllotoxin following fermentation of 92 endophytic fungi isolated from Sinopodophyllum hexandrum, Diphylleia sinensis, and Dysosma veitchii. Of these 92 strains, 6 could produce podophyllotoxin under the conditions used. In 2006, two groups published work with endophytic fungi that upon fermentation produced podophyllotoxin. Puri et al. demonstrated that the fungal endophyte Trametes hirsute, isolated from the rhizome of a Podophyllum hexandrum species, produced podophyllotoxin [77]. The same year Eyberger et al. reported that two strains of the endophyte Phialocephala fortinii that they isolated from $P$. peltatum $L$ also produced podophyllotoxin on subsequent fermentation [80]. Then, in 2008, Kour et al. reported that the endophyte $F$. oxysporum isolated from Juniperus recurva produced podophyllotoxin when fermented [81].

Over the following years, a number of groups have continued to report that endophytic fungi from plants that contain/produce podophyllotoxin, when isolated and fermented outside of the plant, will produce relatively low levels of podophyllotoxin. In 2009, the Spiteller group working with an Aspergillus fumigatus endophyte isolated from another species of Juniperus (Juniperus communis L. Horstmann) reported production of the derivative deoxypodophyllotoxin ( $\triangleright$ Fig. 2) on fermentation [82]. In 2012, Nadeem et al. reported that $P$. hexandrum roots contained a Fusarium solani endophyte, subsequently named $F$. solani P1, that produced podophyllotoxin on fermentation [83]. This publication was followed in 2016 by a report from Liang et al. on a podophyllotoxin-producing isolate of $A$. tenuissima obtained from Sinopodophyllum emodi (Wall) [84]. So, in the years from 2003 to 2016, a fair number of different fungal endophytes from a variety of plant sources have demonstrated their ability to produce small quantities of podophyllotoxin and/or derivatives.

As found with the other plant-derived compounds discussed earlier, these fermentations yielded low levels in the range from $0.5 \mu \mathrm{g} \cdot \mathrm{L}^{-1}$ to $189 \mu \mathrm{g} \cdot \mathrm{L}^{-1}$. However, concentrations of podophyllotoxin could sometimes increase between subculturings, suggesting the metabolite is not present due to carryover from the plant 
[85]. In addition, secoisolariciresinol dehydrogenase (SD) genes in the proposed podophyllotoxin biosynthetic pathway have been found in both $P$. peltatum and the endophyte Phialocephala podophylli (strain PPE7), with the genes characterized in vitro, the first time that the $S D$ gene was characterized in the fungal kingdom [85]. Optimization of production of podophyllotoxin requires more studies on the heterologous expression of genes in this biosynthetic pathway, and the effects of fermentation conditions will hopefully provide insight into metabolic bottlenecks and chemical signals, leading to improved endophytic production of podophyllotoxin [85].

\section{Homoharringtonine}

Early in the second decade of the 20th Century, Chinese researchers reported that the plant Cephalotaxus fortunei Hook-F contained alkaloid fractions with cytotoxic properties [86,87]. Many years later, in 1970, Perdue et al. at the USDA facility at Peoria, Illinois, reported the isolation of a novel anticancer alkaloid, homoharringtonine ( $\bullet$ Fig. 2 ), together with some related ester derivatives found in extracts of the rare Eastern Asian evergreen tree Cephalotaxus harringtonia (Knight ex J. Forbes) K. Koch (Cephalotaxaceae) [88]. Later that same year its structure was published by Powell et al. from the same USDA group [89].

Subsequent studies demonstrated that the mechanism of action of homoharringtonine was by inhibiting protein synthesis at the ribosome level within the $G_{1}$ and $G_{2}$ phases of the cell cycle [90]. The initial clinical compound was developed in the People's Republic of China (PRC) as a racemic mixture of homoharringtonine and harringtonine to treat acute and some resistant myeloid leukemias. The single compound homoharringtonine then entered clinical trials in the USA, leading to the approval of omacetaxine mepeosuccinate (generic name) by the US FDA in 2012 as an antileukemic agent [87]. Whaun and Brown had earlier reported antiparasitic activity of esters of the compound against two chloroquine-resistant Plasmodium falciparum malarial strains [91], though this was well before its approval as an antitumor agent in the USA.

There have been a number of reports of homoharringtonine production by endophytic fungi isolated from plants of the Cephalotaxus genus. All have been reported by research groups in the PRC beginning in 2010. As a result of the inability to access the full publications, except in one case, a determination cannot formally be made as to whether they are multiple reports of the same series of experiments or are actually from different sources [92-94]. Then, in 2016, a publication by Hu et al. claimed that this was the first publication to show such a production, when working with the fungus A. tenuissima $\mathrm{CH} 1307$, an endophyte of Cephalotaxus hainanensis [95]. Four years earlier in 2012, the same endophyte/activity was published by another Chinese group [96], so until the full papers related to the other three reports are available outside of the PRC, the last one is the only one where significant details can be found. Once one or more of these endophytes can be confirmed as a producer of this metabolite, then additional studies must be conducted to determine if or how the fermentation of these endophytes can be used for the industrial production of homoharringtonine.

\section{"Epiphytic" Microbes in the Rhizosphere and Phyllosphere of Plants}

We consider that microbes in the rhizosphere (root tangles and surrounding soil) are similar to epiphytes in being surface microbes rather than endophytes, microbes under the surface of plants. There is no question that chemical signals can proceed in both directions from free-living microbes/epiphytes and their plant "hosts", just as has been reported over the last few years between animal (including human) gut microbiomes and their corresponding central nervous systems [97]. Two review articles, one in 2013 by Bulgarelli et al. in the Annual Reviews of Plant Biology [98] and a more recent one in 2018 by Etalo et al. [99], give generalized and specific examples of the effects of secondary metabolites from rhizosphere bacteria on plant metabolism/immune systems.

We will discuss two recent examples, where the involvement of bacterial species has led to the realization that the plant-sourced anti-tubulin agent maytansine is not a plant product, and also the discovery of significant genetic biosynthetic clusters, reported recently from Arabidopsis thaliana leaf epiphytes.

\section{Maytansine}

Maytansine ( $\bullet$ Fig. 1) was originally thought to be a plant-derived antitumor agent whose mechanism of action was inhibition of tubulin, thus causing cells to arrest at the $G_{2} / M$ phase [100]. The compound was first reported in 1972 from collections of the Ethiopian trees Maytensus serrata (Hochst. Ex A. Rich) and Maytensus ovatus in low yields, and then later from another plant source, Putterlickia verrucosa [101]. What later became important was the early recognition that the basic structure strongly resembled a well-known series of bacterial metabolites, the ansamitocins, and, in particular, ansamitocin P3 ( $\bullet$ Fig. 2).

As can be seen from a comparison of the structures, ansamitocin P3 differs from maytansine by having a different ester at the $\mathrm{C}^{3}$ position. The ansamitocins (other structures not shown) were first reported from fermentation of the bacterium Actinosynnema pretiosum, originally isolated from the Carex species of grassy plants epiphyte [102]. In 2013, ansamitocin P3 was also demonstrated to be a tubulin inhibitor and, like maytansine, also binding at the vinca site on the tubulin dimer [103]. The significant similarities in structures led to the question as to whether maytansine was a plant product or produced via an association between a microbe and its plant host. Since careful inspection showed that none of the biosynthetic genes leading to the production of maytansine could be found in the nominal plant host [104], a reasonable explanation would be that the P3 precursor was produced by an endophyte/epiphyte symbiont in the rhizosphere of the plant, and then subsequently taken up by the plant and converted into maytansine via a simple transesterification. This seemed a plausible hypothesis, as several ansamitocins were present in/produced by eubacteria, higher plants, and mosses, contradicting a common evolutionary theory that natural products are produced by taxonomically related organisms.

Wings et al. subsequently grew axenic cell cultures of $P$. verrucosa and could neither amplify genes involved in maytansine bio- 
synthesis nor culture any maytansine-producing eubacterium outside of its natural habitat [105]. Using suitable molecular techniques, they identified that the $A$. pretiosum ssp. auranticum eubacterium present in the rhizosphere of the plant was involved in maytansine biosynthesis. Using the whole plant system, the A. pretiosum ssp. auranticum eubacterium had the identical 165 rDNA sequence as that of the "parent" maytansine-producing $P$. verrucosa plant [105]. Further genetic searching using other non-maytansine-producing $P$. verrucosa plants showed that they lacked this $16 \mathrm{~S}$ rDNA sequence. The absence of maytansine in plant cell cultures derived from maytansine-producing $P$. verrucosa plants, as well as greenhouse grown Maytenus sp. and Putterlickia sp. plants and their corresponding cell cultures, is consistent with the sequence data [104].

Microorganisms in the rhizosphere of plants in different environments, as well as those in non-rhizosphere communities in the surrounding soil, appear to differ [66], which is a possible explanation as to why maytansine was found in mosses and higher plants. However, ansamitocin-producing plants, meaning the complete "organism including associated microbes", may well contribute to ansamitocin structural diversity via infection of the root system, since only 2 known ansamitocins have been found from eubacteria, while there are 22 known in plants [105]. The example given later under the "Epiphyte Discussion" of discovery of a compound first described from a deep-water bacterium and then found in the phyllosphere of $A$. thaliana might alter the thinking behind the comment above on ansamitocin structural diversity in the future!

In 2014, the Spiteller group published the very significant finding that the true source of maytansine was from a consortium of bacteria (epiphytic, free-living, or endophytic) in the rhizosphere of the maytansine-containing plants $P$. verrucosa and Putterlickia retrospinosa, without any plant involvement other than being the host. Currently, the exact organism(s) performing the reaction remain(s) to be identified [106]. This discovery is not the sole route to maytansine, as in a recent 2016 paper reporting an in-depth investigation of the maytansine-producing Maytenus serrata plant from Cameroon, the same group reported a strong relationship between endogenous "as yet uncultivated microbes" and the production of the desired metabolite, with the required chlorination step occurring in the rhizosphere microbes. However, the biosynthetic starter unit 3-amino-5-hydroxybenzoic acid (AHBA) in maytansine biosynthesis was unexpectedly found to be produced by both the microbes and the plant [107]. However, not all $M$. serrata plants produced maytansine, or possessed the genes to do so, since an $M$. serrata plant now collected in Ghana lacked the AHBA synthase gene. Thus, the geographic area of the "nominal producing plant" as well as the genus and species may have different "effects" on the route(s) to maytansine. This involvement of the Cameroonian plant was not the expected result based on their earlier data, but the evidence is there.

\section{Epiphytes from the phyllosphere}

In 2012, Vorholt, at the ETH in Zurich, published an excellent review on the phyllosphere in Nature Reviews of Microbiology showing in early figures, scanning electron micrographs of bacteria and some fungi on the leaf of the plant $A$. thaliana [108]. An initial calculation in her paper arrives at a figure of $>10^{25}$ bacteria alone worldwide for the phyllosphere's contribution to bacterial diversity, with $>10^{6}$ microbes per $\mathrm{cm}^{2}$ of leaf surface. Then, in 2015, Bai et al. published a report comparing the overlap of root and leaf microbiota in the same plant, giving full details of their methods of isolation and analyses. This was a combined effort on the part of the ETH, the Max Planck Institute in Cologne, and the Institute for Infection Research in Braunschweig [109].

In 2017, Vorholt and colleagues at the ETH published a provocative article in Cell Host and Microbes [110] that contained the following comment: "Taken together, recent data from cultivation-independent investigations indicate that microbial communities do not assemble randomly but establish consistently in a similar pattern year after year. Thus, structuring principles must exist that determine the architecture of various community configurations; however, these are presently insufficiently described". These comments referred to the microbial communities in their $A$. thaliana experimental plants but could apply to any other plant genus/species.

Though starting work before the 2017 paper referred to above, in 2018, Piel and Vorholt, who are both at the Institute of Microbiology at the ETH, published a joint paper demonstrating the biosynthetic potential of the bacterial collection previously reported by Vorholt [111]. This collaboration took advantage of the manifold skill sets that each of the principal authors' groups possessed. As above, a quotation from their article demonstrated the potential from these initial investigations; viz "Genome mining identified more than 1000 predicted natural product biosynthetic gene clusters (BGCs), hundreds of which are unknown compared to the MIBiG database of characterized BGCs. For functional validation, we used a high throughput screening approach to monitor over 50000 binary strain combinations. We observed 725 inhibitory interactions, with 26 strains contributing to the majority of these".

Using current advanced methodologies in order to establish the chemical identities of some of the compounds produced by the most "active" isolate, the BGC-rich Brevibacillus sp. Leaf182 yielded a number of bioactive structures. These included the known streptocidin D, an unusual lysophospholipd named phosphobrevin, together with the previously reported marthiapeptide ( $\vee$ Fig. 3). This latter compound was first reported from the deepsea bacterium Marinactinospora thermotolerans but without a full identification of the relevant BGC [112]. The corresponding BGC was then identified by the ETH group during their isolation of the molecule, with the BGC clusters subsequently added to the MIBiG database. Finally, following on from the bioactivity-driven isolation system used for the three agents referred to above, subsequent use of a genomic mining process (described in detail in the paper) identified the previously unknown cyclic polyketide ( $\vee$ Fig. 3) that they named macrobrevin.

The work described above is only "scratching the surface" of just this collection of plant-leaf associated bacteria, let alone the other $>10^{25}$ bacteria referred to in the opening paragraph of this section. To discover a secondary metabolite from the leaves of A. thaliana, whose original identification/source was from a deepsea thermotolerant microbe, could mean that any commentary on "sole sourcing/occurrence of bioactive metabolites" may well need to be qualified. 

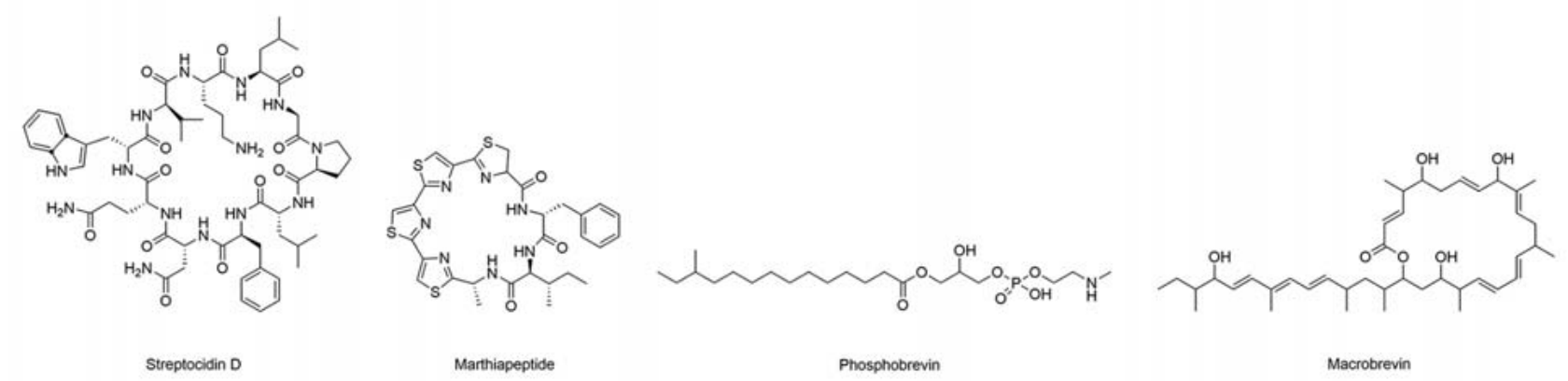

- Fig. 3 Bioactive agents from A. thaliana leaf epiphytes.

\section{Final comments on endophyte/epiphyte compound production}

Perhaps the major encumbrance to studies with these potential sources is the lack of realization by a number of researchers that microbes, irrespective of their nominal isolation source, do not exist in isolation. It is a legacy of the early searches for antibiotics where a pure culture of a "producing organism" was the starting point for increased production, and then followed early attempts at genetic manipulation by treatment with mutagens, including radiation from varied sources. Coupled to modifications in culture and growth conditions, these worked, as can be seen from studies of the increased yields of the base antibiotics such as penicillin cephalosporin and tetracycline.

However, particularly in the roots of plants and within and on the portions of a plant, microbes, irrespective of whether they are prokaryotes or eukaryotes, as mentioned earlier, interact by chemical signals. The lack of an understanding of the natural roles of microbial secondary metabolites (signaling, defense, attack, etc.) limited the search for natural products to readily accessible, but usually limited environments. A multitude of symbiotic relationships remain to be exploited, and understanding the mechanisms of action behind the chemical repertoire involved in symbiont-mediated defense could be key to understanding these interspecies interactions. Such information may ultimately lead to new ways of cultivating symbionts and producing more bioactive compounds, perhaps overcoming the supply problem, which is one of the main reasons why many bioactive natural products do not enter the drug market [113].

We can start addressing the supply problem once larger-scale productive fermentation of symbionts can be achieved. However, interspecies interactions are dynamic and evolve over time, providing new sources for the endless production of new, diverse secondary metabolites, but also providing more problems that need to be addressed.

Within the last 2 to 3 years, there have been a significant number of papers published on how one may exploit the types of interactions discussed above, and, most importantly, describe new methods of searching for microbes producing novel secondary metabolites. The following examples do not formally address endophytes and epiphytes but are indicative of the methods that can be used to help define the methodologies for successful pro- duction of cytotoxic (and other agents) from microbes/hosts. These include, but are not limited to, eliciting secondary metabolism in actinomycetes [114-117], methodologies for identifying the compounds produced [118-122], where they are localized [123], analyses of fungal BGCs to published natural product structures [124, 125], small-scale plate-based techniques for fungal coculture $[126,127]$, on-demand production of secondary metabolites [128], mixed culture of endophytes [129], metabolomics in induced cultures [130-135], use of synthetic biological techniques to further expand the chemical biodiversity discovered [132], a 2016 review on a number of approaches used to study the expression of cryptic BGCs by Zarins-Tutt et al. [136], and a more recent follow-up by Scott and Piel [137].

Finally, on this particular topic, there have been three reports in 2015 to 2016 on products from symbioses in plants, marine organisms, and other animals that should be read by everyone interested in this area. The first is a truly excellent compendium of material from plant and marine invertebrate symbioses [138], the second covers animal-microbe interactions, including the major compounds from insect-microbe symbioses [139], whilst the third discusses the "utility" of such materials as signaling molecules [140]. Although there are later reports on some aspects covered by these three reports, they are not as comprehensive.

\section{In Conclusion}

Hopefully we have demonstrated in this review that the field of natural product drug discovery is still an area of expanded research, but it is no longer just the "playground for natural product chemists and microbiologists". It now requires the very close cooperation of taxonomists, chemical ecologists, agronomists, bioengineers, biochemists, microbiologists, molecular biologists, and chemists to understand how to exploit Nature's chemical and biological diversity. By working together towards a common goal, we will gain a deeper understanding of these symbioses/antagonisms and use them in order to develop new drugs, but it must be pointed out that such research is a long-term project. 


\section{Conflict of Interest}

The authors declare that thay have no conflict of interest. All funding came from personal funds as both are retirees from the $\mathrm{NCl} / \mathrm{NIH}$ and hold honorary positions as NIH Special Volunteers.

\section{References}

[1] Nilsson RH, Ryberg M, Abarenkov K, Sjokvist E, Kristiansson E. The ITS region as a target for characterization offungal communities using emerging sequencing technologies. FEMS Microbiol Lett 2009; 296: 97-101

[2] Kautsar SA, Blin K, Shaw S, Navarro-Muñoz JC, Terlouw BR, van der Hooft JJJ, van Santen JA, Tracanna V, Suarez Duran HG, Andreu VP, SelemMojica N, Alanjary M, Robinson SL, Lund G, Epstein SC, Sisto AC, Charkoudian LK, Collemare J, Linington RG, Weber T, Medema MH. MIBiG 2.0: a repository for biosynthetic gene clusters of known function. Nuc Acids Res 2020; 48: D454-D458

[3] Tan RX, Zou WX. Endophytes: a rich source of functional metabolites. Nat Prod Rep 2001; 18: 448-459

[4] Freeman EM, Marshall WH. The seed-fungus of Lolium temulentum, L., the darnel. Phil Trans R Soc Lond B 1904; 196: 1-27

[5] Petrini AE, Petrini O. Xylarious fungi as endophytes. Sydowia 1985; 38 : 216-234

[6] Stierle A, Strobel G, Stierle D. Taxol and taxane production by Taxomyces andreanae, an endophytic fungus of Pacific yew. Science 1993; 260: 214-216

[7] Stierle A, Strobel G, Stierle D, Grothaus P, Bignami G. The search for a taxol-producing microorganism among the endophytic fungi of the Pacific yew, Taxus brevifolia. J Nat Prod 1995; 58: 1315-1324

[8] Cai LY, Shi FX, Gao X. Preliminary phytochemical analysis of Acanthopanan trifoliatus (L.) Merr. J Med Plant Res 2011; 5: 4059-4064

[9] Kumar NS, Simon N. In vitro antibacterial activity and phytochemical analysis of Gliricidia sepium (L.) leaf extracts. J Pharmacog Phytochem 2016; 5: 131-133

[10] Cao H, Ji Y, Li S, Lu L, Tian M, Yang W, Li H. Extensive metabolic profiles of leaves and stems from the medicinal plant Dendrobium officinale Kimura et Migo. Metabolites 2019; 9: 215

[11] Fuller RW, Cardellina JH II, Kato Y, Brinen LS, Clardy J, Snader KM, Boyd MR. A pentahalogenated monoterpene from the red alga Portieria hornemannii produces a novel cytotoxicity profile against a diverse panel of human tumor cell lines. J Med Chem 1992; 35: 3007-3011

[12] Chen L, Yu B, Zhang Y, Gao X, Zhu L, Ma T, Yang H. Bioactivity-guided fractionation of an antidiarrheal Chinese herb Rhodiola kirilowii (Regel) Maxim reveals (-)-epicatechin-3-gallate and (-)-epigallocatechin-3-gallate as inhibitors of cystic fibrosis transmembrane conductance regulator. PLoS One 2015; 10: e0119122

[13] Nothias LF, Nothias-Esposito M, da Silva R, Wang M, Protsyuk I, Zhang Z, Sarvepalli A, Leyssen P, Touboul D, Costa J, Paolini J, Alexandrov T, Litaudon M, Dorrestein PC. Bioactivity-based molecular networking for the discovery of drug leads in natural product bioassay-guided fractionation. J Nat Prod 2018; 81: 758-767

[14] Baell JB, Nissink JWM. Seven year itch: Pan-Assay Interference Comounds (PAINS) in 2017 - utility and limitations. ACS Chem Biol 2018; 13: 36-44

[15] Bisson J, McAlpine JB, Friesen B, Chen SN, Graham J, Pauli GF. Can invalid bioactives undermine natural product-based drug discovery? I Med Chem 2016; 59: 1671-1690

[16] Li JY, Sidhu RS, Ford E, Hess WM, Strobel GA. The induction of taxol production in the endophytic fungus - Periconia sp. from Torreya grandifolia. J Ind Microbiol 1998; 20: 259-264

[17] Heinig U, Scholz S, Jennewein S. Getting to the bottom of taxol biosynthesis by fungi. Fung Div 2013; 60: 161-170
[18] Chen L, Zhang QY, jia M, Ming QL, Yue W, Rahman K, Qin LP, Han T. Endophytic fungi with antitumor activities: Their occurrence and anticancer compounds. Crit Rev Microbiol 2016; 42: 454-473

[19] Hao X, Pan J, Zhu X. Taxol Producing Fungi. In: Ramawat K, Merillion JM, eds. Natural Products. Berlin: Springer; 2013: 2797-2812

[20] Xiong ZQ, Yang YY, Zhao N, Wang Y. Diversity of endophytic fungi and screening of fungal paclitaxel producer from Anglojap yew, Taxus $x$ media. BMC Microbiol 2013; 13: 71

[21] Somjaipeng S, Medina A, Magan N. Environmental stress and elicitors enhance taxol production by endophytic strains of Paraconiothyrium variabile and Epicoccum nigrum. Enzyme Micro Technol 2016; 90: 69-75

[22] Soliman SS, Tsao R, Raizada MN. Chemical inhibitors suggest endophytic fungal paclitaxel is derived from both mevalonate and non-mevalonatelike pathways. J Nat Prod 2011; 74: 2497-2504

[23] Soliman SSM, Raizada MN. Interactions between co-habitating fungi elicit synthesis of taxol from an endophytic fungus in host Taxus plants. Front Microbiol 2013; 4: 3

[24] Soliman SSM, Trobacher CP, Tsao R, Greenwood JS, Raizada MN. A fungal endophyte induces transcription of genes encoding a redundant fungicide pathway in its host plant. BMC Plant Biol 2013; 13: 93

[25] Soliman SSM, Greenwood JS, Bombarely A, Mueller LA, Tsao R, Mosser DD, Raizada MN. An endophyte constructs fungicide-containing extracellular barriers for its host plant. Curr Biol 2015; 25: 2570-2576

[26] Soliman SSM, Raizada MN. Darkness: a crucial factor in fungal taxol production. Front Microbiol 2018: 9: 353

[27] Stahlhut R, Park G, Petersen R, Ma W, Hylands P. The occurrence of the anti-cancer diterpene taxol in Podocarpus gracilior Pilger (Podocarpaceae). Biochem Syst Ecol 1999; 27: 613-622

[28] El-Sayed ASA, Safan S, Mohamed NZ, Shaban L, Ali GS, Sitohy MZ. Induction of taxol biosynthesis by Aspergillus terreus, endophyte of Podocarpus gracilior Pilger, upon intimate interaction with the plant endogenous microbes. Process Biochem 2018; 71: 31-40

[29] El-Sayed ASA, Mohamed NZ, Safan S, Yassin MA, Shaban L, Shindia AA, Ali GS, Sitohy MZ. Restoring the taxol biosynthetic machinery of Aspergillus terreus by Podocarpus gracilior pilger microbiome, with retrieving the ribosome biogenesis proteins of WD40 superfamily. Sci Rep 2019; 9: 11534

[30] Ismaiel AA, Ahmed AS, Hassan IA, El-Sayed ER, El-Din AAK. Production of paclitaxel with anticancer activity by two local fungal endophytes, Aspergillus fumigatus and Alternaria tenuissima. Appl Microbiol Biotech 2017; 101: $5831-5846$

[31] El-Sayed ER, El-Din AAK, Ismaiel AA, Ahmed AS, Hassan IA. Bioprocess optimization using response surface methodology for production of the anticancer drug paclitaxel by Aspergillus fumigatus and Alternaria tenuissima: Enhanced production by ultraviolet and gamma irradiation. Biocatal Agric Biotechnol 2019; 18: 100996

[32] Yang Y, Zhao H, Barrero RA, Zhang B, Sun G, Wilson IW, Xie F, Walker KD, Parks JW, Bruce R, Guo G, Chen L, Zhang Y, Huang X, Tang Q, Liu H, Bellgard MI, Qiu D, Lai J, Hoffman A. Genome sequencing and analysis of the paclitaxel-producing endophytic fungus Penicillium aurantiogriseum NRRL 62431. BMC Genomics 2014; 15: 69

[33] Hoffman A, Shahidi F. Paclitaxel and other taxanes in hazelnut. J Funct Foods 2009; 1: 33-37

[34] El-Sayed ASA, Ali DM], Yassin MA, Zayed RA, Ali GS. Sterol inhibitor "Fluconazole" enhance the taxol yield and molecular expression of its encoding genes cluster from Aspergillus flavipes. Process Biochem 2019; 76: $55-67$

[35] Bainier G, Sartory A. Étude d'une espèce nouvelle de Sterigmatocystis. Sterigmatocystis flavipes (n. sp.). Bull Soc Mycol de France 1911; 27: 90 97

[36] Kusari S, Singh S, Jayabaskaran C. Rethinking production of Taxol(R) (paclitaxel) using endophyte biotechnology. Trends Biotechnol 2014; 32: $304-311$ 
[37] Ajikumar PK, Xiao WH, Tyo KE], Wang Y, Simeon F, Leonard E, Mucha O, Phon TH, Pfeifer B, Stephanopoulos G. Isoprenoid pathway optimization for Taxol precursor overproduction in Escherichia coli. Science 2010; 330: $70-74$

[38] Ding MZ, Yan HF, Li LF, Zhai F, Shang LQ, Yin Z, Yuan Y]. Biosynthesis of taxadiene in Saccharomyces cerevisiae: selection of geranylgeranyl diphosphate synthase directed by a computer-aided docking strategy. PLoS One 2014; 9: e109348

[39] Zhou K, Qiao K, Edgar S, Stephanopoulos G. Distributing a metabolic pathway among a microbial consortium enhances production of natural products. Nature Biotechnol 2015; 33: 377-383

[40] Wall ME, Wani MC, Cook CE, Palmer KH, McPhail AT, Sim GA. Plant antitumor agents. I. The isolation and structure of camptothecin, a novel alkaloidal leukemia and tumor inhibitor from Camptotheca acuminata. J Am Chem Soc 1966; 88: 3888-3890

[41] Zhang JL, Sharma PL, Li C], Dezube B], Pardee AB, Crumpacker CS. Topotecan inhibits human immunodeficiency virus type 1 infection through a topoisomerase-independent mechanism in a cell line with altered topoisomerase I. Antimicrob Agents Chemother 1997; 41: 977981

[42] Priel E, Showalter SD, Blair DG. Inhibition of human immunodeficiency virus (HTV-1) replication in vitro by noncytotoxic doses of camptothecin, a topoisomerase I inhibitor. AIDS Res Human Retrovir 2009; 7: 65-72

[43] Muggia FM, Creaven P], Hansen HH, Cohen MH, Selawry OS. Phase I clinical trial of weekly and daily treatments with camptothecin (NSC100880): correlation with preclinical studies. Cancer Chemother Rep 1972; 56: 515-521

[44] Moertel CG, Schutt AJ, Reitemeier RJ, Hahn RG. Phase II study of camptothecin (NSC-100880) in the treatment of advanced gastrointestinal cancer. Cancer Chemother Rep 1972; 56: 95-101

[45] Cragg GM, Newman DJ. A tale of two tumor targets: topoisomerase I and tubulin. The Wall and Wani contribution to cancer chemotherapy. J Nat Prod 2004; 67: 232-244

[46] Newman DJ, Cragg GM, Kingston DGI. Natural Products as Pharmaceuticals and Sources for Lead Structures. In: Aldous D, Rognan D, Raboisson P, Wermuth C, eds. The Practice of medicinal Chemistry, 4th ed. Amsterdam: Elsevier; 2015: 102-138

[47] Padmanabha BV, Chandrashekar M, Ramesha BT, Gowda HCH, Gunaga RP, Suhas S, Vasudeva R, Ganeshaiah KN, Shaanker RU. Patterns of accumulation of camptothecin, an anti-cancer alkaloid in Nothapodytes nimmoniana Graham. in the Western Ghats, India: implications for identifying high-yielding sources of the alkaloid. Curr Sci 2006; 90: 95-100

[48] Sharma S, Rathi N, Kamal B, Pundir D, Kaur B, Arya S. Conservation of biodiversity of highly important medicinal plants of India through tissue culture technology-a review. Agric Biol J N Am 2010; 1: 827-833

[49] El-Elimat T, Raja HA, Graf TN, Faeth SH, Cech NB, Oberlies NH. Flavonolignans from Aspergillus iizukae, a fungal endophyte of milk thistle (Silybum marianum). J Nat Prod 2014; 77: 193-199

[50] Shweta S, Shivanna MB, Gurumurthy BR, Shaanker RU, Kumar TRS, Ravikanth G. Inhibition of fungal endophytes by camptothecine produced by their host plant, Nothapodytes nimmoniana (Grahm) Mabb. (Icacinaceae). Curr Sci 2014; 107: 994-1000

[51] Shweta S, Gurumurthy BR, Ravikanth G, Ramanan US, Shivanna MB. Endophytic fungi from Miquelia dentata Bedd., produce the anti-cancer alkaloid, camptothecine. Phytomed 2013; 20: 337-342

[52] Rehman S, Shawl AS, Kour A, Andrabi R, Sudan P, Sultan P, Verma V, Qazi GN. An endophytic Neurospora sp. from Nothapodytes foetida producing camptothecin. App Biochem Microbiol 2008; 44: 203-209

[53] Kusari S, Zuhlke S, Spiteller M. An endophytic fungus from Camptotheca acuminata that produces camptothecin and analogues. J Nat Prod 2009; 72: 2-7

[54] Kusari S, Hertweck C, Spiteller M. Chemical ecology of endophytic fungi: origins of secondary metabolites. Chem Biol 2012; 19: 792-798
[55] Sadre R, Magallanes-Lundback M, Pradhan S, Salim V, Jones AD, DellaPenna D. Metabolite diversity in alkaloid biosynthesis: a multilane (diastereomer) highway for camptothecin synthesis in Camptotheca acuminata. Plant Cell 2016; 28: 1926-1944

[56] Kusari P, Kusari S, Spiteller M, Kayser O. Implications of endophyte-plant crosstalk in light of quorum responses for plant biotechnology. Appl Microbiol Biotechnol 2015; 99: 5383-5390

[57] Pu X, Chen F, Yang Y, Qu X, Zhang G, Luo Y. Isolation and characterization of Paenibacillus polymyxa LY214, a camptothecin-producing endophytic bacterium from Camptotheca acuminata. J Ind Microbiol Biotechnol 2015; 42: 1197-1202

[58] Pu X, Qu X, Chen F, Bao ], Zhang G, Luo Y. Camptothecin-producing endophytic fungus Trichoderma atroviride LY357: isolation, identification, and fermentation conditions optimization for camptothecin production. Appl Microbiol Biotechnol 2013; 97: 9365-9375

[59] Venugopalan A, Srivastava S. Endophytes as in vitro production platforms of high value plant secondary metabolites. Biotech Adv 2015; 33 : 873-887

[60] Venugopalan A, Potunuru UR, Dixit M, Srivastava S. Effect of fermentation parameters, elicitors and precursors on camptothecin production from the endophyte Fusarium solani. Biores Technol 2016; 206: 104-111

[61] Bhalkar BN, Bedekar PA, Patil SM, Patil SA, Govindwar SP. Production of camptothecine using whey by an endophytic fungus: standardization using response surface methodology. RSC Adv 2015; 5: 62828-62835

[62] Bhalkar BN, Patil SM, Govindwar SP. Camptothecine production by mixed fermentation of two endophytic fungi from Nothapodytes nimmoniana. Fungal Biol 2016; 120: 873-883

[63] Soujanya KN, Siva R, Kumara PM, Srimany A, Ravikanth G, Mulani FA, Aarthy T, Thulasiram HV, Santhoshkumar TR, Nataraja KN, Shaanker RU. Camptothecin-producing endophytic bacteria from Pyrenacantha volubilis Hook. (Icacinaceae): A possible role of a plasmid in the production of camptothecin. Phytomed 2017; 36: 160-167

[64] Gueritte F, Fahy J. The Vinca Alkaloids. In: Cragg GM, Kingston DGI, Newman DJ, eds. Anticancer Agents from natural Sources. Boca Raton, FL: Taylor and Francis; 2005: 123-135

[65] Zhang LB, Gou LH, Li H, Zeng S, Shao H, Gu S, Wei R. Preliminary study on the isolation of endophytic fungus of Catharanthus roseus and its fermentation to produce product of therapeutic value. Chin Tradit Herbal Drugs (aka Zongcaoyuo) 2000; 11: 805-807

[66] Gunatilaka AAL. Natural products from plant-associated microorganisms: distribution, structural diversity, bioactivity, and implications of their occurrence. J Nat Prod 2006; 69: 509-526

[67] Yang X, Zhang L, Guo B, Guo S. Preliminary study of a vincristine-producing endophytic fungus isolated from leaves of Catharanthus roseus. Chin Tradit Herbal Drugs (aka Zongcaoyuo) 2004; 35: 79-81

[68] Guo B, Li H, Zhang L. Isolation of an fungus producting vinblastine. J Yunnan Univ Nat Sci 1998; 20: 214-215

[69] Kumar A, Patil D, Rajamohanan PR, Ahmad A. Isolation, purification and characterization of vinblastine and vincristine from endophytic fungus Fusarium oxysporum isolated from Catharanthus roseus. PLoS One 2013; 8: e71805

[70] Kumar A, Ahmad A. Biotransformation of vinblastine to vincristine by the endophytic fungus Fusarium oxysporum isolated from Catharanthus roseus. Biocatal Biotrans 2013; 31: 89-93

[71] Palem PPC, Kuriakose GC, Jayabaskara C. An endophytic fungus, Talaromyces radicus, isolated from Catharanthus roseus, produces vincristine and vinblastine, which induce apoptotic cell death. PLoS One 2016; 10 : e0144476

[72] Anjum N, Chandra R. Endophytic bacteria of Catharanthus roseus as an alternative source of vindoline and application of response surface methodology to enhance its production. Arch Biol Sci 2019; 71: 27-38

[73] Pandey SS, Singh S, Babu CSV, Shanker K, Srivastava NK, Shukla AK, Kalra A. Fungal endophytes of Catharanthus roseus enhance vindoline 
content by modulating structural and regulatory genes related to terpenoid indole alkaloid biosynthesis. Sci Rep 2016; 6: 26583

[74] Podwyssotzki V. Pharmakologische studien über Podophyllum peltatum. Arch Exp Pathol Pharmakol 1880; 13: 29-52

[75] Borsche W, Niemann J. Über Podophyllin. Justus Liebigs Ann Chem 1932; 494: $126-142$

[76] Newman DJ, Cragg GM. Natural products as sources of new drugs from 1981 to 2014. J Nat Prod 2016; 79: 629-661

[77] Puri SC, Nazir A, Chawla R, Arora R, Riyaz-ul-Hasan S, Amna T, Ahmed B, Verma V, Singh S, Sagar R, Sharma A, Kumar R, Sharma RK, Qazi GN. The endophytic fungus Trametes hirsuta as a novel alternative source of podophyllotoxin and related aryl tetralin lignans. J Biotechnol 2006; 122 : 494-510

[78] Liu W, Liu J, Yin D, Zhao X. Influence of ecological factors on the production of active substances in the anti-cancer plant Sinopodophyllum hexandrum (Royle) T.S. Ying. PLoS One 2015; 10: e0122981

[79] Yang X, Guo S, Zhang L, Shao H. Select of producing podophyllotoxin endophytic fungi from podophyllin plant. Nat Prod Res Dev 2003; 15: 419-422

[80] Eyberger AL, Dondapati R, Porter JR. Endophyte fungal isolates from Podophyllum peltatum produce podophyllotoxin. J Nat Prod 2006; 69: 1121-1124

[81] Kour A, Shawl AS, Rehman S, Sultan P, Qazi PH, Suden P, Khajuria RK, Verma $\mathrm{V}$. Isolation and identification of an endophytic strain of Fusarium oxysporum producing podophyllotoxin from Juniperus recurva. World J Microbiol Biotechnol 2008; 24: 1115-1121

[82] Kusari S, Lamshoft M, Spiteller M. Aspergillus fumigatus Fresenius, an endophytic fungus from Juniperus communis L. Horstmann as a novel source of the anticancer pro-drug deoxypodophyllotoxin. J Appl Microbiol 2009; 107: 1019-1030

[83] Nadeem M, Ram M, Alam P, Ahmad MM, Mohammad A, Al-Qurainy F, Khan SI, Abdin MZ. Fusarium solani, P1, a new endophytic podophyllotoxin-producing fungus from roots of Podophyllum hexandrum. African J Microbiol Res 2012; 6: 2493-2499

[84] Liang Z, Zhang J, Zhang X, Li J, Zhang X, Zhao C. Endophytic fungus from Sinopodophyllum emodi (Wall.) Ying that produces podophyllotoxin. J Chromatog Sci 2016; 54: 175-178

[85] Arneaud SLB, Porter JR. Investigation and expression of the secoisolariciresinol dehydrogenase gene involved in podophyllotoxin biosynthesis. Mol Biotechnol 2015; 57: 961-973

[86] Quintás-Cardama A, Cortes ]. Homoharringtonine for the treatment of chronic myelogenous leukemia. Expert Opin Pharmacother 2008; 9: 1029-1037

[87] Kantarjian HM, O'Brien S, Cortes J. Homoharringtonine/omacetaxine mepesuccinate: the long and winding road to Food and Drug Administration approval. Clin Lymphoma Myeloma Leuk 2013; 13: 530-533

[88] Perdue RE jr., Spetzman LA, Rowell RG. Cephalotaxus-source of harringtonine, a promising new anti-cancer alkaloid. Am Horticult Soc 1970; 49 : $19-22$

[89] Powell RG, Weisleder D, Smith CR jr., Rohwedde WK. Structures of harringtonine, isoharringtonine, and homoharringtonine. Tet Lett 1970; 11 : $815-818$

[90] Baaske DM, Heinstein P. Biosynthesis; chemistry; mechanisms of action and resistance cytotoxicity and cell cycle specificity of homoharringtonine. Antimicrob Agents Chemother 1977; 12: 298-300

[91] Whaun JM, Brown ND. Treatment of chloroquine-resistant malaria with esters of cephalotaxine: homoharringtonine. Ann Trop Med Parasitol 1990; 84: 229-237

[92] Han J. Components analysis of homoharringtonine produced by endophytic fungi strain gyzy-20 and optimization for fermentation condition. J Anhui Agric Sci 2010; 34: 22
[93] Han J, Zhao J. Isolation and screening of endophytic fungi strains from Cephalotaxus oliveri Mast to produce homoharringtonine. Acta Agriculturae Boreali-Occidentalis Sinica 2010; 10: 24

[94] Han J, Zhao JH. Isolation and identification of an endophytic homoharringtonine-producing fungi strain gyzy-6 from Cephalotaxus oliveri Mast. Guangdong Agric Sci 2011; 5: 39

[95] Hu X, Li W, Yuan M, Li C, Liu S, Jiang C, Wu Y, Cai K, Liu Y. Homoharringtonine production by endophytic fungus isolated from Cephalotaxus hainanensis Li. World J Microbiol Biotechnol 2016; 32: 110

[96] Liu Y, Liu S, Li Y, Li C. Optimization of homoharringtonine fermentation conditions for Alternaria tenuissima $\mathrm{CH} 1307$, an endophytical fungus of Cephalotaxus mannii Hook. f. J Trop Org 2012; 3: 236-242

[97] Liang S, Wu X, Jin F. Gut-brain psychology: rethinking psychology from the microbiota-gut-brain axis. Front Integr Neurosci 2018; 12: 33

[98] Bulgarelli D, Schlaeppi K, Spaepen S, van Themaat EVL, Schulze-Lefert P. Structure and functions of the bacterial microbiota of plants. Ann Rev Plant Biol 2013; 64: 807-838

[99] Etalo DW, Jeon JS, Raaijmakers JM. Modulation of plant chemistry by beneficial root microbiota. Nat Prod Rep 2018; 35: 398-409

[100] Huang AB, Lin CM, Hamel E. Maytansine inhibits nucleotide binding at the exchangeable site of tubulin. Biochem Biophys Res Comm 1985; 128: $1239-1246$

[101] Kupchan SM, Komoda Y, Court WA, Thomas G], Smith RM, Karim A, Gilmore C], Haltiwanger RC, Bryan RF. Tumor inhibitors. LXXIII. Maytansine, a novel antileukemic ansa macrolide from Maytenus ovatus. J Am Chem Soc 1972; 94: 1354-1356

[102] Higashide E, Asai M, Ootsu K, Tanida S, Kozai Y, Hasegawa T, Kishi T, Sugino $\mathrm{Y}$, Yoneda M. Ansamitocin, a group of novel maytansinoid antibiotics with antitumour properties from Nocardia. Nature 1977; 270: $721-722$

[103] Venghateri JB, Gupta TK, Verma PJ, Kunwar A, Panda D. Ansamitocin P3 depolymerizes microtubules and induces apoptosis by binding to tubulin at the vinblastine site. PLoS One 2013; 8: e75182

[104] Yu JW, Floss HG, Cragg GM, Newman DJ. Ansamitocins (Maytansenoids). In: Cragg GM, Kingston DGI, Newman DJ, eds. Anticancer Agents from natural Products, 2nd Ed. Boca Raton, FL: Taylor and Francis; 2012: 407-427

[105] Wings S, Müller H, Berg G, Lamshöft M, Leistner E. A study of the bacterial community in the root system of the maytansine containing plant Putterlickia verrucosa. Phytochemistry 2013; 91: 158-164

[106] Kusari S, Lamsho M, Kusari P, Gottfried S, Zuhlke S, Louven K, Hentschel U, Kayser O, Spiteller M. Endophytes are hidden producers of maytansine in Putterlickia roots. J Nat Prod 2014; 77: 2577-2584

[107] Kusari P, Kusari S, Eckelmann D, Zuhlke S, Kayser O, Spiteller M. Crossspecies biosynthesis of maytansine in Maytenus serrata. RSC Adv 2016; 6: 10011-10016

[108] Vorholt JA. Microbial life in the phyllosphere. Nat Revs Micro 2012; 10: $828-840$

[109] Bai Y, Müller DB, Srinivas G, Garrido-Oter R, Potthoff E, Rott M, Dombrowski N, Münch PC, Spaepen S, Remus-Emsermann M, Hüttel B, McHardy AC, Vorholt JA, Schulze-Lefert P. Functional overlap of the Arabidopsis leaf and root microbiota. Nature 2015; 528: 364-369

[110] Vorholt JA, Vogel C, Carlstrom Cl, Muller DB. Establishing causality: opportunities of synthetic communities for plant microbiome research. Cell Host Microbe 2017; 22: 142-155

[111] Helfrich EJN, Vogel CM, Ueoka R, Schäfer M, Ryffel F, Müller DB, Probst S, Kreuzer M, Piel J, Vorholt JA. Bipartite interactions, antibiotic production and biosynthetic potential of the Arabidopsis leaf microbiome. Nature Microbiol 2018; 3: 909-919

[112] Zhou X, Huang $H$, Chen $Y$, Tan J, Song $Y$, Zou J, Tian X, Hua Y, Ju J. Marthiapeptide $A$, an anti-infective and cytotoxic polythiazole cyclopeptide from a $60 \mathrm{~L}$ scale fermentation of the deep sea-derived Mari- 
nactinospora thermotolerans SCSIO 00652. J Nat Prod 2012; 75: 2251 2255

[113] Newman DJ. Developing natural product drugs: Supply problems and how they have been overcome. Pharmacol Ther 2016; 162: 1-9

[114] Seyedsayamdost MR, Traxler MF, Clardy J, Kolter R. Old meets new: using interspecies interactions to detect secondary metabolite production in actinomycetes. Methods Enzymol 2012; 57: 89-109

[115] Rutledge PJ, Challis GL. Discovery of microbial natural products by activation of silent biosynthetic gene clusters. Nat Revs Micro 2015; 13: $509-523$

[116] Abdelmohsen UR, Grkovic T, Balasubramanian S, Kamel MS, Quinn RJ, Hentschel U. Elicitation of secondary metabolism in actinomycetes. Biotech Adv 2015; 33: 798-811

[117] Seyedsayamdost MR. Toward a global picture of bacterial secondary metabolism. J Indust Microbiol Biotech 2019; 46: 301-311

[118] Adnani N, Ellis GA, Wyche TP, Bugni TS, Kwan JC, Schmidt EW. Emerging Trends for stimulating the Discovery of natural Products. In: Havlíček V, Spížek J, eds. Natural Products Analysis: Instrumentation, Methods, and Applications. New York: John Wiley \& Sons; 2014: 115161

[119] Duncan KR, Crüsemann M, Lechner A, Sarkar A, Li J, Ziemert N, Wang M, Bandeira N, Moore BS, Dorrestein PC, Jensen PR. Molecular networking and pattern-based genome mining improves discovery of biosynthetic gene clusters and their products from Salinispora species. Chem Biol 2015; 22: 460-471

[120] Luzzatto-Knaan T, Melnik AV, Dorrestein PC. Mass spectrometry tools and workflows for revealing microbial chemistry. Analyst 2015; 140 : 4949-4966

[121] Medema MH, Fischbach MA. Computational approaches to natural product discovery. Nat Chem Biol 2015; 11: 639-648

[122] Mohimani H, Pevzner PA. Dereplication, sequencing and identification of peptidic natural products: from genome mining to peptidogenomics to spectral networks. Nat Prod Rep 2016; 33: 73-86

[123] Oetjen J, Veselkov K, Watrous J, McKenzie JS, Becker M, Hauberg-Lotte L, Kobarg JH, Strittmatter N, Mróz AK, Hoffmann F, Trede D, Palmer A, Schiffler S, Steinhorst K, Aichler M, Goldin R, Guntinas-Lichius O, von Eggeling $\mathrm{F}$, Thiele $\mathrm{H}$, Maedler $\mathrm{K}$, Walch A, Maass P, Dorrestein PC, Takats Z, Alexandrov T. Benchmark datasets for 3D MALDI- and DESIimaging mass spectrometry. Gigascience 2015; 4: 20

[124] Li YF, Tsai KJS, Harvey CJB, Berlew EE, Boehman BL, Findley DM, Friant AG, Gardner CA, Gould MP, Ha JH, Lilley BK, McKinstry EL, Nawal S, Parry RC, Rothchild KW, Silbert SD, Tentilucci MD, Thurston AM, Wai RB, Yoon Y, Aiyar RS, Medema MH, Hillenmeyer ME, Charkoudian LK. Comprehensive curation and analysis of fungal biosynthetic gene clusters of published natural products. Fung Gen Biol 2016; 89: 18-28

[125] Liu J, Liu G. Analysis of secondary metabolites from plant endophytic fungi. Methods Mol Biol 2018; 1848: 25-38
[126] Bertrand S, Azzollini A, Schumpp O, Bohni N, Schrenzel ], Monod M, Gindroc K, Wolfender JL. Multi-well fungal co-culture for de novo metabolite-induction in time-series studies based on untargeted metabolomics. Mol Biosyst 2014; 10: 2289-2298

[127] Bertrand S, Bohni N, Schnee S, Schumpp O, Gindro K, Wolfender JL. Metabolite induction via microorganism co-culture: a potential way to enhance chemical diversity for drug discovery. Biotech Adv 2014; 32: 1180-1204

[128] Bode E, Brachmann AO, Kegler C, Simsek R, Dauth C, Zhou Q, Kaiser M, Klemmt P, Bode HB. Simple “on-demand" production of bioactive natural products. Chembiochem 2015; 16: 1115-1119

[129] Chagas FO, Dias LG, Pupo MT. A mixed culture of endophytic fungi increases production of antifungal polyketides. J Chem Ecol 2013; 39: 1335-1342

[130] Derewacz DK, Covington BC, McLean JA, Bachman BO. Mapping microbial response metabolomes for induced natural product discovery. ACS Chem Biol 2015; 10: 1998-2006

[131] Smanski MJ, Schlatter DC, Kinkel LL. Leveraging ecological theory to guide natural product discovery. J Ind Microbiol Biotechnol 2016; 43: $115-128$

[132] Smanski M], Zhou H, Claesen J, Shen B, Fischbach MA, Voigt CA Synthetic biology to access and expand nature's chemical diversity. Nat Revs Micro 2016; 14: 135-149

[133] van der Lee TAJ, Medema MH. Computational strategies for genomebased natural product discovery and engineering in fungi. Fung Gen Biol 2016; 89: 29-36

[134] Zhang B, Fu Y, Huang C, Zheng C, Wu Z, Zhang W, Yang X, Gong F, Li Y, Chen X, Gao S, Chen X, Li Y, Lu A, Wang Y. New strategy for drug discovery by large-scale association analysis of molecular networks of different species. Sci Rep 2016; 6: 21872

[135] Ziemert N, Alanjary M, Weber T. The evolution of genome mining in microbes - a review. Nat Prod Rep 2016; 33: 988-1005

[136] Zarins-Tutt JS, Barberi TT, Gao H, Mearns-Spragg A, Zhang L, Newman DJ, Goss RJM. Prospecting for new bacterial metabolites: a glossary of approaches for inducing, activating and upregulating the biosynthesis of bacterial cryptic or silent natural products. Nat Prod Rep 2016; 33 : 54-72

[137] Scott TA, Piel ]. The hidden enzymology of bacterial natural product biosynthesis. Nature Rev Chem 2019; 3: 404-425

[138] Florez LV, Biedermann PHW, Engl T, Kaltenpoth M. Defensive symbioses of animals with prokaryotic and eukaryotic microorganisms. Nat Prod Rep 2015; 32: 904-936

[139] Kieft TL, Simmons KA. Allometry of animal-microbe interactions and global census of animal-associated microbes. Proc R Soc B 2015; 282: 0702

[140] Hillman K, Goodrich-Blair H. Are you my symbiont? Microbial polymorphic toxins and antimicrobial compounds as honest signals of beneficial symbiotic defensive traits. Curr Opin Microbiol 2016; 31: 184-190 